\title{
The Musical Analysis of Piano Works "In the Garden of a Chinese Temple--Oriental Fantasia"
}

\section{Min Zhang}

Zaozhuang University, Zaozhuang, Shandong, 277160

Keywords: piano; fantasia; parallel chords; music; creative features

\begin{abstract}
With the blending of Chinese and Western cultures, Western composers have long begun to describe Chinese music content or produce Chinese-style music creation. This paper focuses on an analysis of the British piano composer Albert Caterby's 1923 piano work "In the Garden of a Chinese Temple-Oriental Fantasia" in the hope of summing up features of westerners in the "Chinese style".
\end{abstract}

\section{Introduction}

From the beginning of the 19th century, western music culture began to spread more widely in China, and Chinese music creations also changed with the introduction of western music. At the same time, Chinese classical music works have also gone abroad and they have been familiarized and understood by Westerners. The "Jasmine" fragment in Puccini's opera "Turandot" is the most famous introduction of Chinese melody, but this kind of reference to Chinese music and its creation have long existed. The French composer Francois Copland of the Baroque period, the 27th title of the fourth volume of the "Ancient Piano Suite", was "Chinese". Classical Austrian Carl Carrny wrote a piano song "Brilliant Fantasia". - The Chinese style, and the piano works that touched on Chinese music in the 20th century are even richer. For example, in the United Kingdom, Cyril Scott wrote "Lotus Field" in 1905 and Walter wrote in Germany. In 1919 he wrote "Ancient The Piano Suite of China includes "The Bells of the Prelude Pagoda", "Sad Song - The Night of the Wind", "The Absurd Song - Little Lily", "Halloween - The Boat Song", "The Final Song - The Banquet in the Garden" Five works. As China's influence continues to increase, the level of cultural exchange between China and the West is even closer. This kind of work is even more numerous: Zilpin's Shadowplay, The Piano, Chinese Devotion, Puppet Show, and Carol. In the second half of the 20th century, American Morton Gould wrote a series of Chinese sketches including Great Wall, Prophecy, China Blue, Puppet, Slow Dance - Lotus, and Chinese Fragments. Six works. These works can be found in the book "Chinese Style from the West" edited by Mr. Wang Wen. One of these many works is very noticeable, that is, the British Albert Keitebeier created in 1923 "in the garden of a Chinese monastery - Oriental Fantasia." This piece of work has a beautiful musical melody in the East and a structure with a sense of screen. It has left a deep impression on many piano works.

The British composer Albert Ketelbey was very good at writing popular orchestral works, and some of the music became soundtracks for silent films. He is a very popular English orchestra composer at the beginning of the 20th century. He is good at writing works with a rich oriental culture. His style of music is steady, fresh and gives a very special impression. The father is an engraver. He was a piano player from elementary school and was able to perform on stage when he was 11 years old. At the age of 13, his piano sonata was completed and he received a scholarship from Trinity College in the UK and went to London to learn. Kettle Bay is also proficient in a variety of musical instruments and was once the church organist. Kettle Bay's well-known works of thought, including "Mystic Land in Egypt" and "In Chinese Temple Gardens", are his orchestras and light music. Kettle Bay is well-known in the UK, but there are also criticisms. Since his works are too romantic, his works are not to be considered as skits. Kettle Bay's artwork in his later years has reduced his creativity, even with new wines. The popular repertoire is still such an easy and exotic choreography. From an appreciation point of view, Kitterbeer's works retain the traditional beauty of classical music. Some orchestral music are accompanied by human voices, and the chorus 
occupies a large part in the music and also has the music component of the dance music. Although the length of the work is relatively short, the longest one does not exceed 10 minutes, so it is suitable for both live concert performance and continuous appreciation as a recording. And most of these works have obvious religious emotions. The chorus interspersed between them is solemn and solemn, and some places have oriental colors. The Chinese-style gongs and gongs and sounds of birds appearing in music have added new features to the work. Although there are many light music orchestras, his piano works are also very characteristic. The piano work "The Oriental Fantasia in the Garden of Chinese Monasteries", which is the subject of analysis in this article, is one of the characteristics that can represent his piano creation.

\section{Introduction of Music Content}

Created in 1923. It mainly describes the sound of chanting in the temple - the smell of incense in the air - depicting the melody of a couple - the Manchu-style wedding team marches along the road - attracting people's attention - the sound of temple bells Gradually returning to calm in the main hall, once again heard the chanting sounds, the couple's voice in the birdsong accompanied by the faith of people from temples and street work, the music came to an end.

1) The work begins with the introduction of the four bars (sections 1-4). The rhythm of the two bars is followed by a downward octave octave that leads to the bell of the temple.

2) The first part (Sections 5-20) is entitled "The Voice of the Sutra in the Temple." This piece of music is full of mysterious music. The main melody is in the left-hand and right-hand high-pitched part. And this section of the spectrum is marked with a transliteration of Cantonese in the phrase "a peace of mind will increase faith and earnest devotion." 5-12 Bar Melody In the middle of the left-hand and right-hand high part of the voice is the harmony layer. From the 13th bar, the texture changes, the melody appears in the right hand as a chord, the left hand evolves into a disassembled chord, and the bass " $D$ " is used. The repetitions repeated the sound of the wooden fish that seemed to be chanting or the echo of the bells, but the material and theme did not change, or repeated the music materials in the 5-12 bar.

The second part of the air is filled with incense (21-30), similar to the synaesthesia in Debussy's works, and it uses musical means to express the smell of incense. The left-hand continuous tone "B" is the continuation of the e-minor consonant. The right-handed material uses the chromatic scale to go through a series of detuning to create this kind of fancy mood. It seems that people can really feel the air escaping. Mysterious and devotion, but it is also the flavor of the moment. Sections 23-24 lengthen the rhythm of 21-22 bar is a repetition of the same material, and the use of this material is also closely related to the 3-4 section of the primer. Section 25--30 returns to topic 5-8.

After two sections of transitional music to the third part of the "couple song." This section is very beautiful and charming. It must be very expressive when playing. The melody is completely left-handed, with 8 bars and 16 bars. The unorthodox right-handed vocal chords are played with a light, light stroke to make the left-hand melodious. In this passage, the melody is intoxicating. It seems that there are more than couples, and the birds will be intoxicated.

The fifth part of the music expresses that the Manchu-style team marches along the road. This section starts from the 45th bar to the 59th bar. The theme of the music has only two bars. The repeats and shifts of the two bars in the 45th and 46th bars will be Variations on this theme. The music uses regular accent to express the pace of neat progress. The composer may be interested in representing the rhythmic but slightly humorous sentences with stress.

The sixth part shows the progress of the wedding and attracts people's attention and discussion. The strength of the music continued to accumulate, and eventually it grew to a point where the chords of the Sf appeared, signifying the bells of the temple reverberating, and everything returning calm. In this paragraph, the theme of music is completely five-tone, reflecting the unique charm of oriental music. The music theme is also developed from two sections, namely section 40 and section 41. Based on the melody of the 40th and 41st bars, the theme is moved up eight times and the development is getting faster and faster. The music is promoted to a climax. And the entire left hand is completely using parallelism, so this paragraph is a passage that fully embodies the Chinese 
characteristics in the eyes of Westerners.

The music content of the seventh part (Sections 71-86) is a complete reproduction of the "voices of the chanting in the temple." The contents and musical materials expressed have not changed at all.

The eighth paragraph (sections 87-102) is a complete reproduction of the song of the couple.

The ninth paragraph (103-113) is a comprehensive representation of the theme of the onlookers who appeared in the introduction of the introduction of the wedding ceremony and the preceding.

\section{Musical Analysis}

According to the structure of music, this song uses a complex three-part form to create.

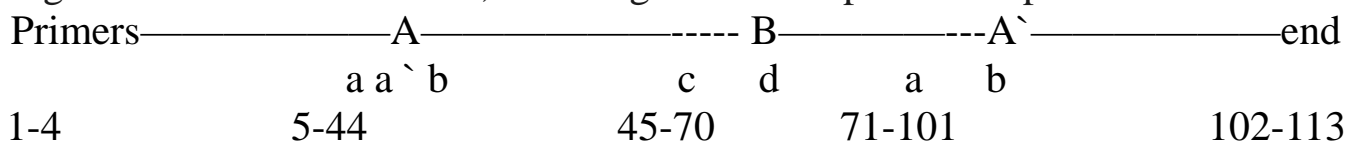

The whole work is based on e-harmonic minors, so the character of the music is not the grand splendour, but the mystery of the minor. It seems to be the scent of incense in the air. The second paragraph of the musical theme, Part D, of the music is written entirely in pentatonic and melody, with the tonality being G-regulating. This is a best way for Westerners to express Eastern music. It is also a very vivid image. The part of the couple's song that was briefly played in the song was reproduced in E major, and the major tone conversion with the lead sounds makes the music clearer and brighter. This section is very beautiful, maybe in the temple. Emotions are not only mysterious. Albert Kettlebey is very good at using exotic melody, which is well reflected in this work, but the main tone of the whole work is e-harmonic minor, which reflects his common musical thinking as a European.

\section{A Large Number of Parallel Chords}

In this song, traditional harmony was used. But the most distinctive feature is the parallel chord progression.

The use of an augmented chord from the introductor is followed by the parallelization of the increasing triad and the beginning of the parallel octave of the left hand after two measures. This may be the need for a solemn atmosphere that the author wants to express, and the parallel octave symbol The chanting or bells of the monastery.

From the 21st bar, the right hand uses parallel six degrees to show the erratic smell of incense. The parallel six degrees creates a sense of instability in the form of semitones. This unstable feeling fits perfectly into the air he wants to describe. The smell of incense, the language of music is just right.

The left hand of the Manchu wedding started with a parallel reduction of four degrees from the 49th bar. For a Westerner, this may be Albert's inner feelings about exotic oriental music. When the Manchu wedding attracted people's attention The left hand began to use parallel five degrees, and this progress lasted 10 measures. From Debussy to Albert, they all seem to love the parallel five degrees and parallel chords. They think that this is particularly capable of expressing the characteristics of China's five tones, not introducing dissonant sounds, and the content of the performance is It is related to monasteries, so the use of parallel chords is often used by Westerners in the expression of oriental music and connotations. This feature also runs through the works analyzed in this article.

\section{The Melody}

The melody of the work is based on the phrase structure of the square type. Although the work was created in the 20th century, there have been a lot of atonal music, such as Schoenberg's expressionism is in full swing, but through this work we find that Albert is indeed a composer who is very good at writing beautiful melody. There are two melody segments that can impress and sing 
in this song. One is the song of a couple, and the other is a music that attracts people's attention. Both of these musical themes are incompatible with the fragmented typical melody characteristics of the 20th century, but are beautiful and melodious melody. They are completely classic melody that can be handed down from the heart. It has to be said that Albert Kettlebey, who is good at light music creation, is a melody master.

\section{The Combination of Piano and Vocal Music}

Beethoven added vocals to the ninth (Chorus) Symphony. After that, Mahler and other composers developed this practice to the extreme. In their opinion, the form of instrumental music added vocals to better express the emotional needs. . Many composers of the 20th century also made such attempts to create works combining instrumental music and vocal music. Albert Keitebei applied this practice to the piano works. In the fifth quarter of the music, he joined the vocals. The dialect in Cantonese was translated as "a peace of mind with increased faith and sincere worship". Adding vocals to the piano's genre and adding lyrics are rare. In a pure piano work, it is seldom able to see the addition of lyrics. This means that you must add chanting tones to highlight your beliefs and affirmations. It can be seen that Albert K. Keither believes that music's form still centers on music content. The relationship between the content and form of this music is self-evident in his works. From the perspective of appreciation, Kettle Bay not only added vocals to his piano works, but also had vocals in several of his orchestras. The chorus occupies a larger proportion in his works. This is what he likes and uses. A method of expression is an important feature of his creation.

Through the analysis of the works, it is easy to see that the British composer Albert Kettlebey used traditional western creative thinking such as musical form, harmony, and tonality in this work, but also integrated the characteristics of Chinese melody. A large number of parallel chords were used, and vocals were added to the piano works, highlighting the importance of emotional expression. This work is a model of the integration of Chinese and Western music language piano works.

\section{References}

[1] Wang Wen, editor of "The Chinese Style from the West: A Chinese-Style Piano Chord by Foreign Composers.” Central Conservatory of Music Press. First edition, June 2013 